\title{
Sistem Monitoring Heart Rate dan Oksigen Dalam Darah Berbasis LoRa
}

\author{
Inda Rusdia Sofiani*1, Rafli Kharisma ${ }^{2}$, Lailis Syafa'ah ${ }^{3}$ \\ Universitas Muhammadiyah Malang, Indonesia
}

INFO ARTIKEL

Alamat Web Artikel:

https://journal.umy.ac.id/index.php/

$\mathrm{mt} /$ article/view/11465

DOI:

https://doi.org/10.18196/mt.v2i2.11465

Data Artikel:

Diterima:

12 Februari 2021

Direview:

20 Februari 2021

Direvisi :

24 Maret 2021

Disetujui :

31 Maret 2021

Korespondensi:

indarusdias05@umm.ac.id

\begin{abstract}
ABSTRAK
Sistem monitoring detak jantung dan oksigen adalah sebuah sistem yang dapat mendeteksi atau memantau kondisi denyut jantung pasien dan kadar oksigen dalam darah dengan memanfaatkan aplikasi android dan jangkauan Lora Ra-02 sebagai komunikasi pengiriman data sehingga dokter dapat memantau kondisi pasien berdasarkan parameter tersebut. Pemeriksaan kadar oksigen dalam darah merupakan parameter tanda vital yang mendasar bagi paramedis dalam menentukan kondisi pasien tersebut. Pemeriksaan heart rate dan oksigen yang dilakukan oleh perawat atau dokter pada umumnya masih menggunakan alat elektrokardiogram dan blood oximeter sehingga masih perlu dicek secara manual dengan rutin dan berkelanjutan. Untuk itu dengan mempertimbangkan keakuratan dan lebih terkontrolnya pengukuran detak jantung dan level oksien secara real time, alat monitoring ini dibuat. Penujian dilakukan melalui keakuratan peniriman data dari alat ke sistem android dan jua dipertimbangkan pula kemungkinan banyaknya data yang hilang dalam setiap pengiriman. Dari hasil pengujian yang telah dilakukan menggunakan 10 parameter didapatkan nilai persentase error heart rate sebesar 4,78\% dan oksigen sebesar 1,94\% dan berdasarkan 5 kategori pengujian. Secara keseluruhan terdapat kekurangan pembacaan yang dipenaruhi jarak transmitter ke receiver.
\end{abstract}

Kata Kunci: Monitoring System, Heart Rate, Oxygen Levels (Sp02), LoRa Ra-02

\begin{abstract}
The heart rate and oxygen monitoring system IS USED TO detect or monitor the patient's CONDITIONS. Examination of oxygen levels in the blood is VITAL for paramedics in determining the patient's condition. From the tests using 10 parameters, the percentage value of THE ERROR HEART RATE IS 4.78\%, AND OXYGEN IS $1.94 \%$. Based on 5 test categories, the overall data can be read by the sensor CORRECTly.
\end{abstract}

Keywords: Monitoring System; Heart Rate; Oxygen Levels (Sp02); LoRa Ra-02

\section{PENDAHULUAN}

Sistem monitoring heart rate dan oksigen adalah sebuah sistem yang dapat mendeteksi atau memantau kondisi denyut jantung pasien dan kadar oksigen dalam darah sehingga nantinya dokter dapat memantau kondisi pasien mengalami gangguan pernafasan. Laju denyut jantung orang dewasa yang normal berkisar antara 60 sampai $100 \mathrm{bpm}$, kelainan denyut jantung dapat terjadi ketika lajunya kurang dari $60 \mathrm{bpm}$ yang dikenal sebagai bradikardia. Selain itu, kelainan denyut jantung juga dapat terjadi ketika lajunya melebihi $100 \mathrm{bpm}$ yang dikenal sebagai takikardia [1]. Nilai normal saturasi oksigen adalah $95 \%$ sampai $100 \%$, nilai saturasi oksigen dibawah $85 \%$ menandakan bahwa jaringan tidak mendapat cukup oksigen sehingga pasien membutuhkan evaluasi lebih lanjut dan nilai saturasi oksigen rendah (kurang dari 70\%) merupakan kondisi yang membahayakan jiwa pasien [2]. Pemeriksaan heart rate dan oksigen yang dilakukan oleh perawat atau dokter pada umumnya menggunakan alat elektrokardiogram dan blood oximeter. Alat ini banyak digunakan karena mampu mengukur aktivitas yang dihasilkan oleh denyut jantung dan oksigen sehingga dapat membantu dokter untuk memonitoring kondisi kesehatan pasien melalui data hasil pengukuran alat tersebut. 


\section{Sofiani, Kharisma, Syafa'ah \\ Sistem Monitoring Heart Rate dan Oksigen Dalam Darah Berbasis LoRa}

Beberapa penelitian yang terkait dengan sistem monitoring detak jantung telah diusulkan diantaranya sistem monitoring detak jantung dan suhu tubuh menggunakan arduino. Hasil penelitian ini didapatkan data jumlah detak jantung per menit terhadap usia pasien baru lahir sampai lebih dari 70 tahun menggunakan sensor EKG (AD8232) yang nantinya sinyal detak jantung yang dihasilkan akan diolah oleh modul arduino dan diteruskan ke LCD atau komputer server melalui kabel data serial plotter [3]. Selain itu penelitian selanjutnya adalah Rancang Bangun Alat Monitoring Jumlah Denyut Nadi / Jantung Berbasis Android. Hasil penelitian ini menggunakan sensor pulse yang datanya akan di olah oleh modul mikrokontroller arduino yang dihubungkan ke Bluetooth HC-05 dan nantinya data atau pembacaan dari sensor akan dikirimkan ke smartphone, dari data hasil pengujian terhitung stabil pada saat detik 18-30 setelah alat dipasangkan pada jari [4]. Penelitian selanjutnya yaitu Desain Alat Ukur Denyut Jantung dan Saturasi Oksigen Pada Anak Menggunakan Satu Sensor. Hasil penelitian ini didapatkan nilai perbandingan denyut jantung dan oksigen menggunakan sensor MAX30100, alat komersial dan menggunakan pengukuran secara manual, dimana didapatkan nilai persentase eror pada denyut jantung diatas 5\% dan persentase eror oksigen dalam darah sebesar 2,6\% [5].

Sistem monitoring heart rate dan oksigen menggunakan modul komunikasi Lora Ra-02 dan dipantau menggunakan apikasi yang merupakan suatu usaha untuk mempermudah kerja paramedik untuk mengontrol kondisi pasien.

\section{METODE PENELITIAN}

Pada bagian ini akan dijelaskan secara singkat implementasi sistem yang digunakan. Gambaran sistem ini digunakan untuk mempermudah dan memperjelas atau mengetahui keluaran dan harapan dari perancangan sistem tersebut.

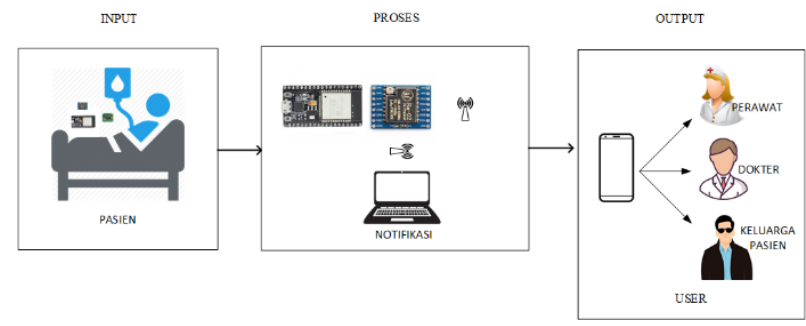

Gambar 1. Diagram Blok Sistem Monitoring Heart Rate Dan Oksigen

\subsection{Perancangan Input}

Secara umum Perancangan input terdiri dari berbagai macam komponen yang mendukung untuk proses pengambilan data, dimana terdapat Sensor MAX30100 yang diletakkan pada ujung jari pasien yang berfungsi untuk mendeteksi heart rate dan oksigen dalam darah yang ada pada tubuh pasien. Dan yang kedua adalah ESP8266, NodeMCU 8266 adalah salah satu jenis mikrokontroller yang digunakan untuk mengolah data yang dihasilkan dari pembacaan sensor melaui pin-pin yang sudah disediakan sekaligus sebagai mikrokontroller yang dikhususkan untuk mengirim data menggunakan modul LoRa, Berikutnya adalah Arduino IDE, disini Arduino IDE berfungsi sebagai compiler dari NodeMCU 8266 yang digunakan untuk mentransfer program yang sudah dibuat di software Arduino IDE ke dalam memori mikrokontroller. Setelah dilihat dari alur diatas bisa diperjelas lagi dengan gambar 2 perancangan alat dibawah ini.

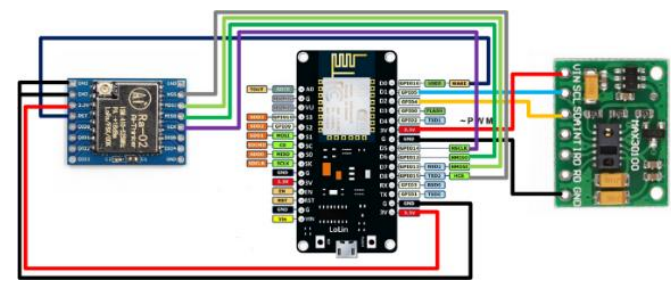

Gambar 2. Perancangan Input 


\subsection{Perancangan Proses}

Perancangan proses terdiri dari berbagai macam komponen yang berguna sebagai piranti pengolahan dala sebelum terbaca pada user yang sudah ada. Pada bagan proses yang dimana terdapat NodeMCU 8266 adalah mikrokontroller yang dimana dapat memancarkan jaringan yang nantinya akan diterima oleh pengguna sebagai media monitoring heart rate dan kadar oksigen dalam darah, kedua yaitu modul komunikasi LoRa Ra-02 yang berfungsi sebagai device transmitter yang digunakan sebagai penerima sinyal yang sudah dikirimkan oleh LoRa Ra-02 receiver, terakhir yaitu komputer yang difungsikan sebagai tempat atau server penyimpanan data yang sudah diterima oleh device transmitter. Pada proses perancangan input dan proses dibutuhkan software Arduino IDE dan XAMPP. Software Arduino IDE adalah software compiler yang disediakan oleh arduino yang digunakan untuk memasukkan program yang sudah dibuat ke dalam sistem arduino. software ini dapat berjalan pada operasi sistem berbasis Linux, MAC OS, dan Windows. Setelah dilihat dari alur diatas bisa diperjelas lagi dengan gambar perancangan alat dibawah ini.

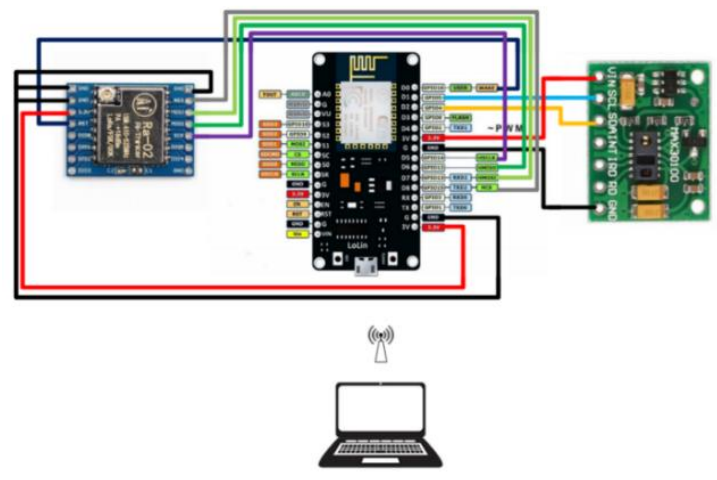

Gambar 3. Perancangan Proses

\subsection{Perancangan Output}

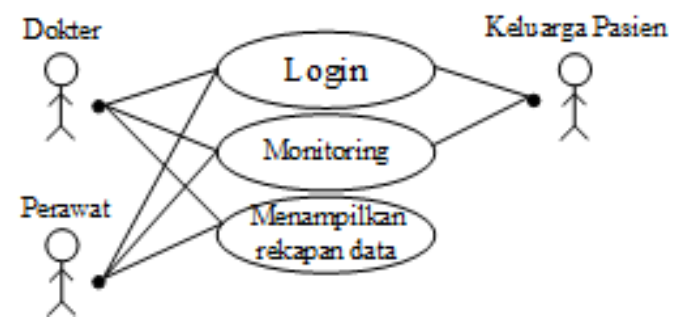

Gambar 4. Use Case Diagram

Pada perancangan output terdapat 3 pengguna terakhir yang dapat mengakses data denyut jantung dan kadar oksigen dari pasien melalui aplikasi yang ada di smartphone, tiga pengguna itu yaitu dokter, perawat, dan keluarga pasien. Tiga pengguna tersebut diberikan akses untuk memantau kondisi pasien agar data yang didapat dari pengukuran dapat terbaca pada aplikasi. Keluarga pasien diberikan akses monitoring 10 data terakhir, sehingga ketika pasien tidak ada yang menjaga pasien, masih dapat terpantau dengan baik. Dokter dan perawat juga memiliki akses untuk membuka data hasil rekapan monitoring yang sebelumnya sudah terbaca oleh sensor, sehingga data tersebut dapat digunakan sebagai acuan tindakan apa yang akan diambil oleh perawat dan dokter selanjutnya. 
Sofiani, Kharisma, Syafa'ah

Sistem Monitoring Heart Rate dan Oksigen Dalam Darah Berbasis LoRa

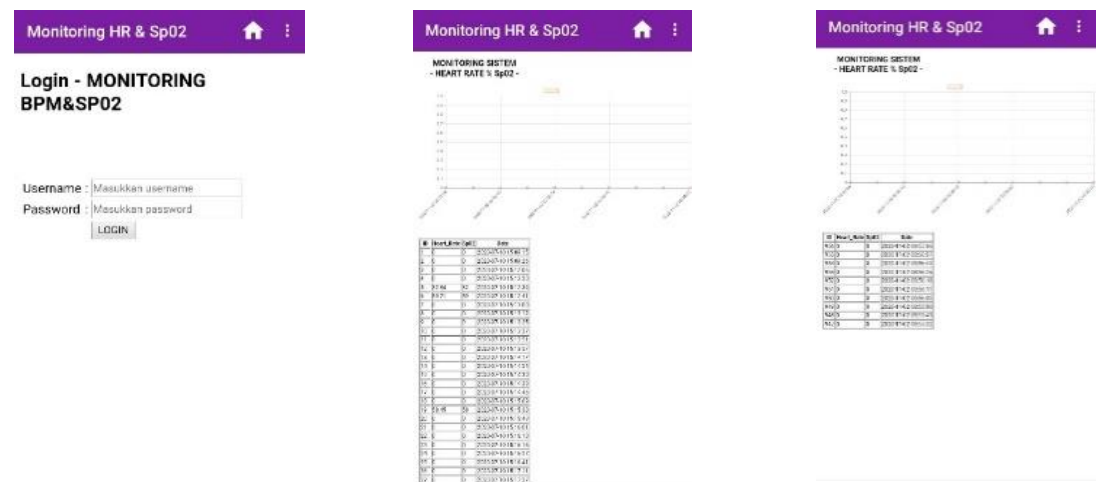

Gambar 5. Desain Tampilan Android

Gambar 5 menunjukkan implementasi dari tampilan android yang dapat diakses oleh keluarga pasien, dokter, dan perawat. Terdapat 3 tampilan yaitu halaman login, tampilan android dokter dan perawat, dan tampilan android keluarga pasien. Setiap user akan mendapatkan akun user dan password untuk dapat monitoring heart rate dan oksigen sesuai dengan data dari sensor yang dipasang pada tubuh pasien.

\section{HASIL DAN PEMBAHASAN}

Pada bagian ini akan mengulas perihal proses pengujian ESP 8266, pengujian sensor MAX30100, pengujian database serta hasil pengujian dari keseluruhan sistem yang sebelumnya telah dibahas. Pembahasan ini mencakup kinerja sistem secara keseluruhan. Setelah mendapatkan hasil pengujian maka langkah selanjutnya adalah menganalisa terhadap setiap tahapan pengujian, sesuai dengan tujuan pengujian.

Pada tahap ini adalah awal dari pengujian yaitu melakukan pengujian pada ESP 8266 dengan cara memastikan tegangan dikeluarkan sesuai dengan datasheet alat tersebut. Berikut adalah tahapan pengujian sistem yang telah dibuat:

\subsection{Pengujian ESP 8266}

Pada tahap ini adalah awal dari pengujian NodeMCU 8266 yang bertujuan untuk mengetahui apakah operasi sistem pada mikrokontroller ESP 8266 dapat berfungsi sebagai mana mestinya. Pada pengujian pin output ESP 8266 akan dilakukan untuk menegetahui berapa tegangan keluaran yang dikeluarkan dari pin tersebut. Pada pengukuran ini menggunakan pin $3 \mathrm{~V}$. Pada pengujian output ESP 8266 pada kondisi aktif atau dihubungkan dengan sumber daya dapat menghasilkan output $3.276 \mathrm{~V}$.

\subsection{Pengujian Sensor MAX30100}

Percobaan sensor MAX30100 dengan spesifikasi RCWL-0530 dilakukan dengan cara menempelkan ujung jari manis ke permukaan sensor. Dilakukan beberapa rangkaian secara bertahap maka didapatlah hasil dari pengujian sensor MAX30100 yang dapat dilihat pada serial monitor Arduino seperti pada gambar 6.

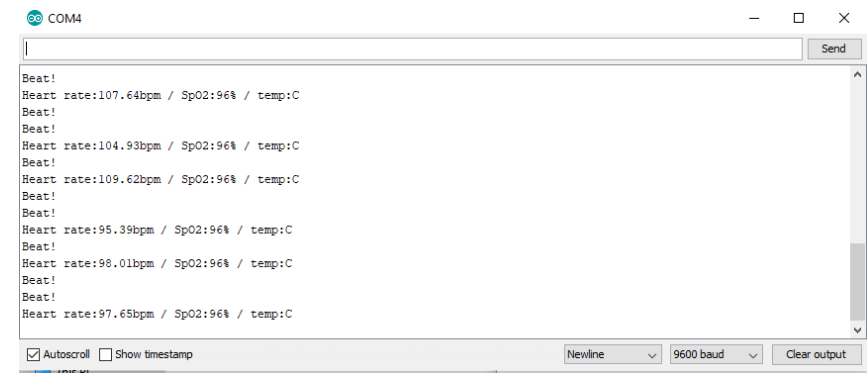

Gambar 6. Hasil Pengujian Sensor MAX30100

Medika Teknika : Jurnal Teknik Elektromedik Indonesia, Vol 02 No. 2, April 2021 | 56 
Didalam tabel 1 terdapat hasil pengujian yang dapat dilihat pada serial monitor arduino yang berasal dari sensor MAX30100, dimana dilakukan berbagai ujicoba dengan cara menempelkan semua ujung jari tangan kanan dan kiri untuk menguji data yang dihasilkan dari alat ukur tersebut.

Tabel 1. Tabel Data Hasil Pengujian Heart Rate (Bpm)

\begin{tabular}{|c|c|c|c|c|}
\hline \multirow{2}{*}{ Pengujian } & \multirow{2}{*}{ Subjek } & $\begin{array}{l}\text { Pengukuran } \\
\text { dengan alat }\end{array}$ & $\begin{array}{c}\text { Pengukuran } \\
\text { Manual }\end{array}$ & \multirow{2}{*}{ Presentase Error (\%) } \\
\hline & & $\begin{array}{l}\text { Heart Rate } \\
(\mathrm{Bpm})\end{array}$ & $\begin{array}{l}\text { Heart Rate } \\
(\mathrm{Bpm})\end{array}$ & \\
\hline 1 & Ibu jari tangan kanan & 89 & 96 & 7,29 \\
\hline 2 & Jari telunjuk tangan kanan & 95 & 96 & 1,04 \\
\hline 3 & Jari tengah tangan kanan & 90 & 97 & 7,21 \\
\hline 4 & Jari manis tangan kanan & 93 & 95 & 2,1 \\
\hline 5 & Jari kelingking tangan kanan & 114 & 96 & 8,33 \\
\hline 6 & Ibu jari tangan kiri & 91 & 96 & 5,2 \\
\hline 7 & Jari telunjuk tangan kiri & 97 & 96 & 1,04 \\
\hline 8 & Jari tengah tangan kiri & 92 & 97 & 5,15 \\
\hline 9 & Jari manis tangan kiri & 98 & 96 & 2,08 \\
\hline \multirow[t]{2}{*}{10} & Jari kelingking tangan kiri & 103 & 95 & 8,42 \\
\hline & Rata-rata error & & & 4,78 \\
\hline
\end{tabular}

Pada tabel 1 didapatkan hasil pengujian dengan menggunakan sensor MAX30100 dengan pengujian manual, untuk mengetahui persentase nilai error yang dihasilkan berdasarkan sepuluh parameter yang diuji, didapatkan nilai rata-rata error sebesar $4,78 \%$.

Tabel 2. Tabel Data Hasil Pengujian Oksigen Sp02 (\%)

\begin{tabular}{ccccc}
\hline \multirow{2}{*}{ Pengujian } & Subjek & $\begin{array}{c}\text { Pengukuran } \\
\text { Sensor }\end{array}$ & $\begin{array}{c}\text { Pengukuran } \\
\text { dengan alat } \\
\text { komersial }\end{array}$ & \multirow{2}{*}{ Presentase Error (\%) } \\
\cline { 2 - 4 } & Sp02 (\%) & Sp02 (\%) & \\
\hline 1 & Ibu jari tangan kanan & 97 & 97 & 0 \\
2 & Jari telunjuk tangan kanan & 96 & 98 & 2,04 \\
3 & Jari tengah tangan kanan & 96 & 98 & 2,04 \\
4 & Jari manis tangan kanan & 95 & 98 & 3,06 \\
5 & Jari kelingking tangan kanan & 99 & 97 & 2,06 \\
6 & lbu jari tangan kiri & 94 & 98 & 4,08 \\
7 & Jari telunjuk tangan kiri & 96 & 98 & 2,04 \\
8 & Jari tengah tangan kiri & 97 & 98 & 1,02 \\
9 & Jari manis tangan kiri & 96 & 97 & 1,03 \\
10 & Jari kelingking tangan kiri & 96 & 98 & 2,04 \\
& Rata-rata error & & & 1,94 \\
\hline
\end{tabular}

Pada tabel 2 didapatkan data hasil pengujian kadar oksigen dengan melakukan perbandingan pengukuran dari sensor dan pengukuran menggunakan pulse oximeter, dari sepuluh data yang diuji didapatkan persentase nilai rata-rata error sebesar $1,94 \%$.

Tabel 3. Tabel Data Hasil Dan Analisis Pengujian Sensor MAX30100

\begin{tabular}{|c|c|c|c|c|}
\hline No & Kondisi & Pengujian & Heart Rate (Bpm) & Sp02 (\%) \\
\hline \multirow{3}{*}{1} & \multirow{3}{*}{ Kurang Sehat } & Jari Telunjuk & 98 & 97 \\
\hline & & Jari Tengah & 102 & 97 \\
\hline & & Jari Manis & 89 & 94 \\
\hline \multirow{3}{*}{2} & \multirow{3}{*}{ Sehat } & Jari Telunjuk & 89 & 96 \\
\hline & & Jari Tengah & 91 & 96 \\
\hline & & Jari Manis & 84 & 97 \\
\hline \multirow{3}{*}{3} & \multirow{3}{*}{ Setelah Makan } & Jari Telunjuk & 81 & 96 \\
\hline & & Jari Tengah & 79 & 96 \\
\hline & & Jari Manis & 87 & 95 \\
\hline \multirow{3}{*}{4} & \multirow{3}{*}{ Setelah Olahraga } & Jari Telunjuk & 114 & 99 \\
\hline & & Jari Tengah & 99 & 98 \\
\hline & & Jari Manis & 102 & 99 \\
\hline \multirow{3}{*}{5} & \multirow{3}{*}{ Bangun Tidur } & Jari Telunjuk & 69 & 96 \\
\hline & & Jari Tengah & 72 & 97 \\
\hline & & Jari Manis & 65 & 97 \\
\hline
\end{tabular}




\section{Sofiani, Kharisma, Syafa'ah \\ Sistem Monitoring Heart Rate dan Oksigen Dalam Darah Berbasis LoRa}

Pada data hasil pengujian sensor MAX30100 dilakukan percobaan berdasarkan lima kondisi yang berbeda dengan diambil dari tiga jari yang mempunyai nilai persentase error paling sedikit dibandingkan dengan yang lainnya, didapatkan nilai seperti pada tabel 3 dimana setiap kondisi didapatkan nilai yang berbeda-beda, didapatkan pada konsisi setelah olahraga nilai heart rate lebih tinggi dibandingkan kondisi yang lainnya, dan pada kondisi bangun tidur didapatkan nilai heart rate yang lebih kecil dibandingkan kondisi lainnya. namun pembacaan sensor tersebut sangat dianjurkan untuk meminimalisir gerakan agar data yang terbaca oleh sensor tidak mengalami perubahan yang signifikan.

\subsection{Pengujian Lora Ra-02}

Pengujian ini menggunakan modul ESP 8266, sensor MAX30100 dan LoRa Ra-02 untuk mengecek media komunikasi yang digunakan untuk mengirimkan data sensor dari transmitter kepada receiver, hal ini dilakukan dengan cara menghubungkun pin-pin yang ada pada ESP 8266, sensor MAX30100, dan LoRa-Ra02 yang sudah diatur sedemikian rupa untuk dijadikan sebagai transmitter, kemudian untuk receiver hanya menggunakan ESP 8266 dan LoRa Ra-02. Dapat dilihat pada gambar 7

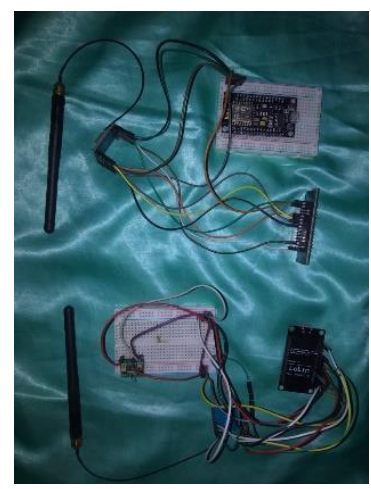

Gambar 7. Lora Ra-02 Transmitter dan Receiver

\subsection{Pengujian Aplikasi Monitoring}

Pengujian aplikasi ini bertujuan untuk memastikan data yang terbaca dan sudah terkirim dapat dibaca atau dimonitoring langsung menggunakan aplikasi yang sudah tersedia. terdapat tampilan halam login yang ada pada aplikasi, didalam halaman login terdapat kolom username dan password sehingga ketika user ingin masuk untuk memantau data yang berada dalam aplikasi, user tersebut harus memasukkan pengguna dan kata sandi yang sebelumnya sudah terdaftar, kemudian langkah terakhir pilih atau klik LOGIN pada aplikasi. Apabila user salah dalam memasukkan username atau password maka akan keluar notifikasi "login gagal username dan password salah". Terdapat 3 pengguna yaitu dokter, perawat, dan keluarga pasien serta hak akses yang sudah ditentukan. Aplikasi ini didalamnya akan menampilkan grafik dan data pada tabel seperti ditunjukkan pada gambar 8 .

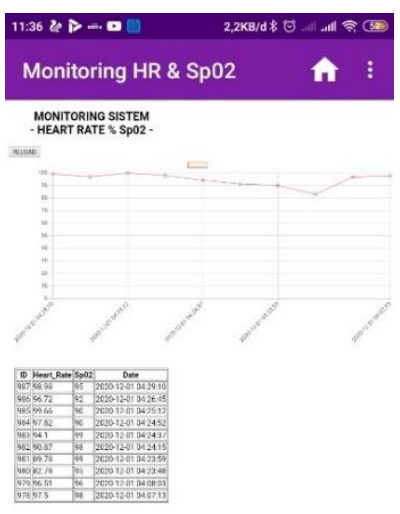

Gambar 8. Tampilan Aplikasi Monitoring 


\section{Sofiani, Kharisma, Syafa'ah}

Sistem Monitoring Heart Rate dan Oksigen Dalam Darah Berbasis LoRa

\subsection{Pengujian secara keseluruhan dari system}

Setelah dilakukan pengujian yang dilakukan secara satu persatu maka hal yang selanjutnya dilakukan adalah pengujian dari alat secara menyuluh mulai dari sistem program dalam pengujian sensor MAX30100 hingga pengujian aplikasi. Pengujian ini dilakukan agar dapat mengetahui apakah sistem yang sudah dibuat dapat berjalan dengan baik. Berikut adalah hasil dari alat monitoring heart rate dan kadar oksigen dari berbagai jarak dapat dilihat dari tabel berikut ini.

Tabel 4. Hasil Monitoring Heart Rate \& Oksigen Sp02

(Line Of Sight)

\begin{tabular}{|c|c|c|c|c|}
\hline No & Jarak & Hasil Pada & Hasil Pada & Kesimpulan \\
\hline & Iransmitter - Recelver & & Aplikasi & \\
\hline 1. & 10 meter & Terdeteksi & Terdeteksi & \\
\hline 2. & 100 meter & Terdeteksi & Terdeteksi & $\begin{array}{l}\text { Pada Jarak } 10 \mathrm{~m}-600 \mathrm{~m} \\
\text { receiver masih bisa menerima } \\
\text { data yang dikirimkan dari } \\
\text { tranmitter dengan kuat yang } \\
\text { masih bagus. }\end{array}$ \\
\hline 3. & 300 meter & Terdeteksi & Terdeteksi & \\
\hline 4. & 600 meter & Terdeteksi & Terdeteksi & \\
\hline 5. & 900 meter & Terdeteksi & Terdeteksi & $\begin{array}{l}\text { Pada jarak } 900 \mathrm{~m}-1 \mathrm{~km} \text { data } \\
\text { dapat diterima, namun dari } \\
\text { kecepatan data sangat lambat. }\end{array}$ \\
\hline 6. & 1 kilometer & Terdeteksi & Terdeteksi & \\
\hline 7. & 1,02 kilometer & $\begin{array}{c}\text { Tidak } \\
\text { Terdeteksi }\end{array}$ & $\begin{array}{c}\text { Tidak } \\
\text { Terdeteksi }\end{array}$ & $\begin{array}{l}\text { Pada jarak } 1,02 \mathrm{~km} \text { data sudah } \\
\text { tidak dapat diterima oleh } \\
\text { receiver yang disebabkan oleh } \\
\text { kemampuan pengiriman data } \\
\text { dari LoRa Ra-02. }\end{array}$ \\
\hline
\end{tabular}

Pada tabel pengujian pada area line of sight didapatkan hasil pengukuran secara keseluruhan pada jarak tertentu. Didapatkan pada jarak 10 meter sampai dengan 1 kilometer data masih dapat terbaca dan pada jarak 1,02 kilometer data sudah tidak dapat terbaca.

\section{ANALISA}

Tabel 5 menunjukkan adanya penaruh pengiriman data terhadap jarak dan lokasi.

Tabel 5. Hasil Monitoring Heart Rate \& Oksigen Sp02

(di dalam ruangan)

\begin{tabular}{|c|c|c|c|c|}
\hline No & $\begin{array}{c}\text { Jarak } \\
\text {. }\end{array}$ & & & Kesimpulan \\
\hline & Transmitter - Receiver & Database & Aplikasi & \\
\hline 1. & 1 meter & Terdeteksi & Terdeteksi & \\
\hline 2. & 3 meter & Terdeteksi & Terdeteksi & $\begin{array}{l}\text { Pada Jarak } 1 \mathrm{~m}-6 \mathrm{~m} \text { receiver masih bisa } \\
\text { menerima data yang dikirimkan dari } \\
\text { tranmitter dengan kuat sinyal yang } \\
\text { masih bagus. }\end{array}$ \\
\hline 3. & 5 meter & Terdeteksi & Terdeteksi & \\
\hline 4. & 6 meter & Terdeteksi & Terdeteksi & \\
\hline 5. & 7 meter & Terdeteksi & Terdeteksi & $\begin{array}{c}\text { Pada jarak } 7 \text { meter receiver masih bisa } \\
\text { menerima data dari transmitter } \\
\text {,namun dari kecepatan data sangat } \\
\text { lambat. }\end{array}$ \\
\hline 6. & 8,25 meter & $\begin{array}{c}\text { Tidak } \\
\text { Terdeteksi }\end{array}$ & $\begin{array}{c}\text { Tidak } \\
\text { terdeteksi }\end{array}$ & $\begin{array}{l}\text { Pada jarak 8,25 meter data sudah tidak } \\
\text { dapat diterima oleh receiver yang } \\
\text { disebabkan oleh kemampuan } \\
\text { pengiriman data dari LoRa Ra-02. }\end{array}$ \\
\hline
\end{tabular}

Medika Teknika : Jurnal Teknik Elektromedik Indonesia, Vol 02 No. 2, April 2021 | 59 


\author{
Sofiani, Kharisma, Syafa'ah \\ Sistem Monitoring Heart Rate dan Oksigen Dalam Darah Berbasis LoRa
}

Terdeteksi atau tidak terdeteksinya data yang terbaca dapat dipengaruhi oleh beberapa faktor yaitu diantaranya adalah :

\title{
a. Jarak
}

Dalam proses pengambilan data pada sensor yang akan dikirimkan oleh transmitter ke receiver, proses pengiriman data sangat dipengaruhi oleh jarak antara kedua piranti tersebut, ini dibuktikan dengan adanya percobaan pada tabel 4 dan tabel 5 yang dimana data dapat terkirim hanya dengan jangkauan tertentu saja.

\section{b. Lokasi}

Lokasi sangat mempengaruhi tingkat keberhasilan dari pengiriman data antara transmitter dan receiver. Pada pengujian tugas akhir ini dilakukan dua pengujian yaitu line of sight dan didalam ruangan, dengan didapatkan perbedaan dari aspek jarak atau jangkauan pengiriman data lebih luas line of sight dibandingkan pengujian didalam ruangan, dikarenakan pada area line of sight tidak ada penghalang yang dapat mempengaruhi sinyal dibandingkan dengan didalam ruangan yang material dinding pada ruangan dapat menghambat sinyal sehingga data tidak dapat terkirim dengan benar.

\section{c. Jaringan Internet dan Penempatan Sensor}

Jaringan internet dapat mempengaruhi pembacaan data pada aplikasi monitoring HR \& Oksigen Sp02, karena aplikasi yang dibuat membutuhkan terkoneksi dengan internet agar data yang sudah terkirim pada database dapat terbaca pada aplikasi yang sudah terinstal pada smartphone. Penempatan sensor yang diletakkan pada ujung jari pasien juga sangat penting, karena gerakan pada ujung jari dapat mempengaruhi proses pembacaan sensor sehingga sangat disarankan agar ujung jari pasien tetap menempel pada sensor agar data yang terbaca semakin akurat.

Dari pengujian alat secara meyeluruh didapatkan analisa bahwa pada perancangan pada seluruh sistem berjalan dengan baik. Dari sistem pada perancangan program untuk pengambilan data dari sensor yang kemudian dikirimkan ke dalam database dan dimonitoring langsung pada aplikasi dapat berjalan dengan baik.

\section{KESIMPULAN}

Dari hasil penelitian dan analisa pengujian sistem yang telah dibuat, dapat diambil beberapa kesimpulan, yakni Sensor MAX30100 dapat membaca parameter nilai heart rate dan kadar oksigen pada pasien, dengan 10 parameter didapatkan nilai persentase error heart rate sebesar 4,78\% dan oksigen sebesar $1,94 \%$. Data yang sudah terbaca juga dapat dipantau menggunakan aplikasi android. Lora Ra-02 sebagai modul komunikasi mampu mengirimkan data dengan (line of sight) pada jarak kurang dari 1,02 kilometer dan jarak yang berada didalam ruangan pada jarak kurang dari 8,25 meter.

Dari hasil pengujian sistem terdapat beberapa kekurangan. Sebaiknya pada saat pengiriman data jarak antara transmitter dan receiver lebih dekat agar proses pengiriman data lebih cepat. Selain itu juga perlu ditambahkan beberapa sensor lagi agar dapat membaca data lebih dari 1 orang. Penelitian lebih lanjut sebaiknya cenderung menggunakan media komunikasi yang lebih sesuai dengan kebutuhan.

\section{DAFTAR PUSTAKA}

[1] Dena Anugrah, Arjuni Budi Pantjawati. 2016, "Rancang Bangun Pengukuran Laju Detak Jantung Berbasis PLC Mikro", J. Electronics, vol. 1, no. 3

[2] Ari Andriani, Rodhi Hartono. 2013, "Saturasi Oksigen Dengan Pulse Oximetry Dalam 24 jam Pada Pasien Dewasa Terpasang Ventilator Di Ruang ICU Rumah Sakit Panti Wilasa Citarum Semarang", JNJ, vol. , no. 1 
[3] Sollu, Tan Suryani, Alamsyah. 2018, 3 Agustus. Sistem Monitornig Detak Jantung dan Suhu Tubuh Menggunakan Arduino. Palu. Techno.com.

[4] Fachrul Rozie, Hadary Ferry. 2019. Rancang bangun Alat Monitoring Jumlah Denyut Nadi / jantung Berbasis Android. Pontianak. Media.neliti.com.

[5] Qahar, Adhar Nur. 2018. Desain Alat Ukur Denyut Jantung dan Saturasi Oksigen Pada Anak Menggunakan Satu Sensor. Yogyakarta. Universitas Islam Yogyakarta.

[6] N. Hidayati, L. Dewi, M. F. Rohmah, and S. Zahara, "Prototype Smart Home Dengan Modul NodeMCU ESP8266 Berbasis Internet of Things (IoT)," Tek. Inform. Univ. Islam Majapahit, pp. 1-9, 2018.

[7] Hartono Jogiyanto. 1999. Pengenalan Komputer Dasar Ilmu KOmputer, Pemrograman, Sistem Informasi dan Intelegensi Buatan. Yogyakarta: ANDI Yogyakarta.

[8] I. T. M. Daeng, N. . Mewengkang, and edmon R. Kalesaran, "Penggunaan Smartphone Dalam Menunjang Aktivitas Perkuliahan Oleh Mahasiswa Fispol Unsrat Manado," E-Journal Acta Diurna, vol. 6, no. 1, pp. 1-15, 2017.

[9] M. Liandana, "Penerapan Teknologi LoRa pada Purwarupa Awal Wearable Device," Res. Comput. Inf. Syst. Technol. Manag., vol. 2, no. 2, p. 40, 2019, doi: 10.25273/research.v2i02.5191.

[10] Mochamad Fajar Wicaksono, Hidayat. 2017. Mudah Belajar Mikrokontroller Arduino. Bandung. Informatika Bandung.

[11] R. Safitri, "Simple Crud Buku Tamu Perpustakaan Berbasis Php Dan Mysql :LangkahLangkah Pembuatan," Tibanndaru J. Ilmu Perpust. dan Inf., vol. 2, no. 2, p. 40, 2018, doi: 10.30742/tb.v2i2.553. 